Open Access

\title{
A study on the current status and strategies for improvement of web accessibility compliance of public institutions
}

\author{
Kyung-Ran Noh', Eui-Seob Jeong ${ }^{2^{*}}$, Young-Bok You' ${ }^{2}$ Sun-Joo Moon ${ }^{3}$ and Mun-Bok Kang ${ }^{4}$
}

\footnotetext{
* Correspondence: esjng@kisti.re.kr ${ }^{2}$ SMEs Support Center, Korea Institute of Science and Technology Information, 66, Hoegi-ro,

Dongdaemun-gu, Seoul (130-741), South Korea

Full list of author information is available at the end of the article
}

\begin{abstract}
Background: The circulation of information through the Internet allows us to promptly and conveniently deliver information. However, it is also causing a simultaneous occurrence of digital information gap and cultural lag phenomena. The gap in the ability to freely access and use Web site contents using the Internet is affecting not only the digital information gap, it also affects the competitiveness of individuals. In Korea, pursuant to Article 21 of the "Act on the Prohibition of the Discrimination against the Disabled and the Relief of their Rights" and Article 14 of its enforcement ordinances enforced from 2008, Web-accessibility compliance for each agency has been gradually made mandatory. Even if a Web-accessibility certification mark has been obtained, some Web sites are involved in legal disputes because of their violation of the Anti-Discrimination Act for the Disabled, which has been recently enforced.

Methods: This study examines the actual situation of the compliance by conducting web accessibility assessment. 25 websites among the Korean public institutions in the science and technology field were selected and were assessed manually according to KWCAG 2.0.

Results: According to experts assessments using web accessibility requirement of KWCAG 2.0, 'Perceivable' shows the highest compliance rate (68\%). 'Operable,' 'understandable,' or 'Robust' shows the compliance rates of $64.5 \%, 59.2 \%$, and $28.0 \%$ respectively.
\end{abstract}

Conclusions: Based on the findings of this study, some suggestions are presented to improve web accessibility compliance of the sites that received a web-accessibility certification mark from the National Information Society Agency in Korea.

\section{Introduction}

The advent of the internet is changing everything in politics, economics, society, and culture into forms that have never been imagined in the existing society. Now, the internet is no longer a matter of choice. Rather, it has become the essential means of survival that should be utilized for us to live in a modern society (Hyun and Kim 2008).

The circulation of information through the internet allows us to promptly and conveniently deliver information. However, it is also causing a simultaneous occurrence of digital information gap and cultural lag phenomena. The gap in the ability to freely

\section{Springer}

(C) 2015 Noh et al. This is an Open Access article distributed under the terms of the Creative Commons Attribution License (http:// creativecommons.org/licenses/by/4.0), which permits unrestricted use, distribution, and reproduction in any medium, provided the original work is properly credited. 
access and use website contents using the internet is affecting not only the digital information gap, it also affects the competitiveness of individuals.

The age group of internet users continuously widens along with the increased trend of the number of domestic internet users. As such, the current age group of internet users has been expanded to include people in their prime and the elderly, which in the past only included those who were in their $20 \mathrm{~s}$ and $30 \mathrm{~s}$. The number of the aged internet users is increasing, and the pattern of their internet use also becomes more diverse.

As the percentage of the elderly generation increases more than ever, Korea, which has already become an aging society, is worrying about the possibility of a continuous increase in information gap among the elderly. Moreover, there is also the possibility of this group becoming a part of information-vulnerable class of people. The social and economic gap caused by the digital information gap is creating inequality and serious social conflicts. One of the major causes of such digital information gap is the noncompliance with web accessibility.

As the range of web users is gradually expanding to include the disabled or the old and weak, advanced countries-such as the United States, Canada, Australia, and Europe-enacted laws on web accessibility at the beginning of 2000. This was conducted through the policy of information gap resolution. Such allowed everyone to freely and equally access, as well as use, all the information provided by a website under any technical environment, even if they do not have professional knowledge. In the United States, state-of-the-art information technology enterprises, such as IBM, Microsoft, and Oracle, including the White House home page, strictly follow the principle of accessibility. On their home pages, "pop-up windows" and "moving pictures" are not used because they might be confusing for people who are suffering from mental disorders. In the United Kingdom, an administrative institution who is charge of the entire e-government business has already prepared the duties that should be observed by the governmental websites at the end of 1999. From November 2000, Japan has also made it compulsory for all public offices and institutions to comply with "Web-content accessibility guidelines," which was created by the Ministry of Posts and Telecommunications in November 2000 (Park et al. 2010).

Also in Korea, pursuant to Article 21 of the "Act on the Prohibition of the Discrimination against the Disabled and the Relief of their Rights" and Article 14 of its enforcement ordinances enforced from 2008, web accessibility compliance for each agency has been gradually made mandatory. Consequently, the public and private websites should comply with web accessibility from April 11, 2013.

In Korea, it is not easy for the blind or the elderly to access websites using PCs or smart phones. After a compensation suit was filed against four public institutions and enterprises on November 29, 2012-the first of such incident in Korea-to the effect that web accessibility should be guaranteed and that the discriminative act should be remedied, a series of lawsuits took place against medical institutions, such as hospitals, as well as airlines, and even financial institutions such as banks (News Wire 2013; Kim and Ryu 2010). It is also expected that a series of lawsuits will occur in the future because web accessibility compliance by all public institutions or private enterprises would have been made mandatory as the "Act on the Prohibition of the Discrimination against the Disabled and the 
Relief of their Rights" (hereinafter referred to as the Anti-Discrimination Act for the Disabled) has been enforced more widely from April 11, 2013.

The National Information Society Agency in Korea is operating a certification system that grants the level of web accessibility and offers web accessibility certification mark to excellent websites that complied with the web accessibility standard guidelines to allow any person (including the disabled or the elderly) to use their sites without causing inconvenience. The number of websites that received web accessibility quality certification increased from 15 in 2007 to 127 in 2013.

Even if a web accessibility certification mark has been obtained, some websites are involved in legal disputes because of their violation of the Anti-Discrimination Act for the Disabled, which has been recently enforced. Accordingly, this study will suggest a way to improve web accessibility by surveying the actual situation with regard to the web accessibility compliance of websites that received a Web accessibility certification mark from the National Information Society Agency in Korea. Moreover, this study will also identify items that, so far, lack compliance.

\section{Backgrounds}

\section{Concept and necessity of web accessibility}

Sir. Tim Berners Lee, the father of the Web, argued that "The power of the web lies in its universality. The essential element of the web is to allow all people to easily access information and share it, regardless of their disability." Thus, Lee also emphasized web accessibility in the basic philosophy of the web.

Web accessibility means guaranteeing all users equal access to all information provided by websites under any technical environment even for those without the professional ability. It also means allowing all people to easily use IT devices or services (Hyun and Kim 2008). For example, it means that Macintosh and Linux OS, as well as Microsoft OS users, including browser users of Firefox, Opera, Lynx, and Explorer can equally access internet information.

Web accessibility is a legal requirement in Korea and major advanced countries such as the US and the UK. It is applied not only to desktop computers but also to mobile devices (Jeong et al. 2013a). However, people have a wrong perception that web accessibility is just for the disabled. It is true that web accessibility compliance benefits the disabled the most, however it needs to be recognized that compliance to it also provides as much convenience to ordinary people when they use web contents. As such, it is not only for the disabled or the elderly (Lee and Lee 2007; Kang et al. 2011; Jung and Hong 2014).

The greatest importance of web accessibility is that all users can have an equal opportunity in using websites. The benefits that can be obtained through web accessibility compliance are as follows (Hyun and Choi 2003; National Information Society Agency 2003).

First, the number of various user groups can be expanded through web accessibility compliance. In other words, if web accessibility is secured, the number of users who can efficiently use websites will also increase. In the aspect of business, web accessibility compliance can remove obstacles that restrict the customers' use of websites and result in a sales increase effect through the former.

Second, the websites that obtained web accessibility can have the advantage of being able to provide web contents without great difficulty using the latest devices, 
including any IT device that will appear in the future. In other words, PC and mobile access to web contents can be guaranteed.

Third, if the level of web accessibility is improved, a significant effect can be produced in designing and planning websites. Ultimately, it can also promote convenience in the process of search engine indexing, site reorganizing, and producing multilingual versions. Moreover, it can also secure convenience in producing an additional site in other language version.

Fourth, cost-saving effects can be achieved. At the initial stage of web accessibility compliance, a significant amount of time and financial costs are invested in existing websites to understand the concept of web accessibility and implement compliance. However, various utilities that are necessary for site operation can be secured through web accessibility compliance. Thus, in the long run, cost-saving effects can be achieved.

Fifth, websites that considered web accessibility can provide an equal opportunity to all users. If the range of website application including possible situations are expanded, a greater number of opportunities to use websites are provided to more users. Therefore, web accessibility compliance does not only provide the disabled or the elderly with the opportunity to participate in social activities, it can also help more people process their necessary works with more ease.

Lastly, web accessibility compliance can improve the image of enterprises or institutions, enabling them to achieve a positive PR effect. At this point, wherein the social responsibility of enterprises or institutions is emerging as an important issue, relevant websites can function as an important means of PR for image improvement as people would generally think that their website took web accessibility in consideration.

\section{Web accessibility standard guideline}

The standards to assess web accessibility include the international and domestic standards. The international standard is WCAG (Web Content Accessibility Guidelines), which was created by W3C. It is composed of 64 detailed guidelines under 14 guidelines, and its detailed guidelines are classified into Importance 1, Importance 2, and Importance 3. The domestic standard is KWCAG (Korean Web Content Accessibility Guidelines), which was created in reference to Importance 1 of WCAG and Article 508 of the Rehabilitation Act of the United States. For the compliance of the related institutions, the KWCAG 2.0 was developed in December 2010 as the Korean national standard in consideration of the domestic situations. It revolves around the 12 guidelines of WCAG 2.0, which was created by W3C, and the Importance 1 guideline for success.

KWCAG 2.0 includes the technical specifications for the improvement of web content accessibility, and it is composed of three steps: Principle, Guideline, and Requirement. Within these steps are the four principles for improving web accessibility, the 13 guidelines for compliance with each principle, and the 22 requirements to check the compliance of relevant guidelines.

KWCAG 2.0 was prepared to help website designers and operators, including web content developers, to understand easily and comply with the technical implementation method in accordance with the national standard when they build and operate websites. With this, it will allow the disabled or the elderly to access and use web contents as equally and freely as the ordinary people (Jeong et al. 2013b) (see Tables 1 and 2). 
Table 1 Classification of the importance of the W3C Web Contents Accessibility

\begin{tabular}{llll}
\hline Importance & Importance 1 & Importance 2 & Importance 3 \\
\hline Concept & Must & Should & May \\
Definition & Must comply & Should comply & May comply \\
Significance & -Fulfillment of basic & -Removal of grave defects & -Removal of slight defects \\
& $\begin{array}{l}\text { requirements } \\
\text {-Guarantee of web }\end{array}$ & -Increase in web accessibility & -Improvement of web \\
& accessibility & accessibility \\
& -Access to web contents is & -Causes difficulty in accessing & -Causes inconvenience in \\
& impossible in case of & web contents in case of & accessing web contents in case \\
noncompliance & noncompliance & of noncompliance \\
\hline
\end{tabular}

Source: Joo (2009), "A Study on the Current Situation of Web Accessibility of the Public Institutions and IT Conglomerates," Korea Computer Information Society Journal 14(1): 175-187

\section{Web accessibility and open innovation}

Chesbrough et al. (2006) defines that Inward Open Innovation is the essential component in continuous creation of innovation which not only takes the internal research results to the market, but also brings in the outstanding external technology results to the enterprise. For this end, a variety of methodologies can be leveraged including technology purchase, reverse engineering, new employment of external technologists, strategic alliances and others.

Yun et al. (2014), by singular conceptualization of multiplication of extent and depth of open innovation, made attempts for more objective analysis of practical contents and change progress of open innovation in particular companies as well as particular companies in certain regions. Both chronological analysis and static analysis of extent

Table 2 Comparison of W3C WCAG 2.0 and KWACG 2.0 Web Contents Accessibility Guidelines

\begin{tabular}{|c|c|c|c|}
\hline Principle & W3C WCAG 2.0 & KWACG 2.0 & Remarks \\
\hline \multirow[t]{4}{*}{ 1. Perceivable } & 1.1 Replacement text & 1.1 Replacement text & \\
\hline & 1.2 Time-based media replacement contents & $\begin{array}{l}1.2 \text { Multimedia } \\
\text { replacement means }\end{array}$ & \\
\hline & 1.3 Contents with no loss of information or structure & & \\
\hline & $\begin{array}{l}1.4 \text { Easily visible and audible contents with a } \\
\text { division in front/background color }\end{array}$ & 1.3 Clarity & \\
\hline \multirow[t]{4}{*}{ 2. Operable } & $\begin{array}{l}2.1 \text { All the functions can be operated on the } \\
\text { keyboard }\end{array}$ & $\begin{array}{l}2.1 \text { Keyboard } \\
\text { accessibility }\end{array}$ & \\
\hline & 2.2 Provides sufficient time & $\begin{array}{l}\text { 2.2 Provides } \\
\text { sufficient time }\end{array}$ & \\
\hline & 2.3 Prevents light-sensitive seizure & $\begin{array}{l}2.3 \text { Prevents light- } \\
\text { sensitive seizure }\end{array}$ & \\
\hline & 2.4 Provides navigation & 2.4 Easy navigation & \\
\hline \multirow[t]{4}{*}{ 3. Understandable } & 3.1 Legibility & 3.1 Legibility & \\
\hline & 3.2 Predictability & 3.2 Predictability & \\
\hline & & $\begin{array}{l}3.3 \text { Logicality of } \\
\text { contents }\end{array}$ & $\begin{array}{l}1.3 \text { of WCAG } \\
2.0\end{array}$ \\
\hline & 3.3 Input help & 3.4 Input help & \\
\hline \multirow{2}{*}{$\begin{array}{l}\text { 4. Robust } \\
\text { (Progressive } \\
\text { technology) }\end{array}$} & $\begin{array}{l}\text { 4.1 Maximizes the compatibility with web display } \\
\text { devices including supplementary devices }\end{array}$ & $\begin{array}{l}\text { 4.1 Grammatical } \\
\text { compliance }\end{array}$ & \\
\hline & & $\begin{array}{l}4.2 \text { Web application } \\
\text { accessibility }\end{array}$ & \\
\hline
\end{tabular}

Source : Web Accessibility Laboratory. http://www.wah.or.kr/participation/guide.asp, Korea Communications Commission. Korean Web Contents Accessibility Guideline 2.0 
and level of open innovation in particular time period were attempted, and that new open innovation can be measured in more strategic levels from analysis of innovation status and differences of open innovation of competing companies.

Hoover (2003) conducted the analysis on the factors that how IT professionals made the difference in the adoption and selection of web accessibility functions in light of the disabled users. In research methodology, analysis was conducted from both dependent variables, people (adopters) adopting innovation of web accessibility as well as nonadopters and independent variable groups of three characters of education level, organization characters, and innovation characters that influence the accessibility innovation. Research revealed that four variables of education level, capacity (organization capability of innovation implementation), value (organizational attitude and confidence), observation probability(to extent that innovation results can be seen by others) made the influences on the adoption of accessibility innovation.

Weigel et al (2014) developed Innovation Adoption Behavior by combining planned behavioral theory and diffusion theory. Using the methodology, research results of correlated existing 58 meta analysis demonstrated that attitude, consistency, relative advantages, perceived behavior control, observation probability, subjective faith and trial probability influences innovation adoption, and that complexities have little influences.

\section{Methods}

\section{Selection of web accessibility assessment targets}

Targeting the websites of public institutions that maintain a web accessibility certification mark after being a recent recipient of web accessibility certification from the National Information Society Agency, the professional web accessibility institution in Korea, this study will examine the actual situation of the compliance by conducting web accessibility assessment and suggest a way to improve it.

The National Information Society Agency in Korea is operating a certification system that certifies the level of web accessibility and gives a web accessibility certification mark to excellent websites that complied with web accessibility standard guidelines, thus allowing the disabled and the elderly to experience no inconvenience in using their websites. More importantly, it targets governmental public institutions and private enterprises that operate websites, which provide IT service through the internet (see Table 3).

The problem is that even if the institutions receive a web accessibility certification mark, they can be always involved in lawsuits if the disabled think that they are discriminated. The number of websites that received a web accessibility certification mark from the National Information Society Agency is 127 in 2013. Among them, 27 websites (RE01-RE25) of the public institutions in the science \& technology field were selected as assessment targets in this study.

\section{Web accessibility assessment method and assessment items}

The common methods for web accessibility assessment are an automated assessment method that uses automation tools and an expert assessment method by which the experts can manually assess requirements. As governmental public institutions and private enterprises that have obtained accessibility certifications are the targets of this study, it has adopted a manual assessment method by which the experts can assess in accordance with the Web accessibility principle. 
Table 3 Websites of Web accessibility Assessment Target Institutions in Korea

\begin{tabular}{|c|c|}
\hline Name & Site Address \\
\hline Representative home page of the Korea Gas Technology Corporation & kogas-tech.co.kr \\
\hline Representative home page of the National Science \& Technology Council & old.nstc.go.kr \\
\hline Representative home page of the National Institute of Horticultural \& Herbal Science & nihhs.go.kr \\
\hline $\begin{array}{l}\text { National Institute of Environmental Research, Chemical Accident Emergency Response } \\
\text { Information System }\end{array}$ & ceis.nier.go.kr \\
\hline Korean home page of the Institute for Basic Research & ibs.re.kr/kr \\
\hline $\begin{array}{l}\text { Korea Agency of Education, Promotion and Information Service in Food, Agriculture, Forestry, } \\
\text { and Fisheries, Bio Resource Information Service }\end{array}$ & bris.go.kr \\
\hline Daegu Metropolitan City, Science Education Institute, Gifted Education Support Center & gifted.dise.go.kr \\
\hline Daegu Metropolitan City, Science Education Institute, Cyber Science Hall & cyber.dise.go.kr \\
\hline presentative home page of the Daegu Education Research and Information Institute & derii.go.kr \\
\hline $\begin{array}{l}\text { Representative home page of the Korea Research Council for Industrial Science and } \\
\text { Technology }\end{array}$ & istk.re.kr \\
\hline National IT Industry Promotion Agency, Certified Electronic Address Home page & npost.kr \\
\hline Representative home page of the Chungcheongbuk-do Educational Information Center & cbei.go.kr \\
\hline Representative home page of the Pyeongtaek City Agricultural Technology Center & cypap.net \\
\hline Employment support video of the Korea Employment Information Service & jobvideo.or.kr \\
\hline Representative home page of the Korea Institute of S\&T Evaluation and Planning & kistep.re.kr \\
\hline The Korea Transport Institute, Freight Transport Market Research Center & roft.koti.re.kr \\
\hline Korea Health and Welfare Information Service, National Health Information Portal & health.mw.go.kr \\
\hline Korea Health and Welfare Information Social Service, Electronic Voucher Portal & socialservice.or.kr \\
\hline Korea National Council on Social Welfare, Social Welfare Education Information System & e-ssn.com \\
\hline Korea Association for ICT Promotion and Wise User & wiseuser.go.kr \\
\hline Korea Local Information Research \& Development Institute, Local Finance Open System & lofin.mopas.go.kr \\
\hline Representative home page of the Korea Institute of Patent Information & kipi.or.kr \\
\hline Korea Intellectual Property Rights Information Service & kipris.or.kr \\
\hline Representative home page of the Korea Institute of Ocean Science \& Technology & kiost.ac \\
\hline Korea Environmental Industry \& Technology Institute, Eco-Labeling Certification System & el.keiti.re.kr \\
\hline
\end{tabular}

Source: National Information Society Agency, Web accessibility Research Center, Certified Sites (http://www.wah.or.kr/Certification)

As the Korean Web Content Accessibility Guidelines (KWCAG) was revised into the 2.0 version in December 2009, this study mainly intends to assess the content accessibility of the websites in order to identify whether the 13 website Accessibility Guidelines are complied with. KWCAG 2.0 is largely classified into four principlesPerceivable, Operable, Understandable, and Robust in the internet's web contents. A manual assessment was conducted on a total of 13 guidelines and 20 requirements such as the three guidelines and five requirements for Principle 1 based on KWCAG 2.0; the four guidelines and eight requirements for Principle 2; the four guidelines and five requirements for Principle 3; and the two guidelines and two requirements for Principle 4.

Table 4 shows related principles and manual assessment sub-items, and marked compliance-assessment items with $\mathrm{O}$ or $\mathrm{X}$. Two items, such as "text contents brightness contrast" and "error correction function," which were difficult to be manually assessed by experts, were excluded from assessment items. 
Table 4 KWCAG 2.0 Principle and Inspection Contents

\begin{tabular}{|c|c|c|c|}
\hline Principle & Guideline & Requirement & $\begin{array}{l}\text { Compliance } \\
\text { Assessment }\end{array}$ \\
\hline \multirow[t]{6}{*}{ 1. Perceivable } & 1.1 Replacement text & $\begin{array}{l}\text { 1.1.1 Provision of proper replacement } \\
\text { text }\end{array}$ & $\circ$ \\
\hline & $\begin{array}{l}1.2 \text { Multimedia replacement } \\
\text { means }\end{array}$ & 1.2.1 Provision of subtitle & $\circ$ \\
\hline & 1.3 Clarity & $\begin{array}{l}\text { 1.3.1 Perception of content irrelevant } \\
\text { to color }\end{array}$ & $\circ$ \\
\hline & & 1.3.2 Provision of clear instructions & $\circ$ \\
\hline & & $\begin{array}{l}\text { 1.3.3 Text contents' brightness and } \\
\text { contrast }\end{array}$ & $x$ \\
\hline & & $\begin{array}{l}\text { 1.3.4 Prohibition of the use of } \\
\text { background sound }\end{array}$ & ० \\
\hline \multirow[t]{8}{*}{ 2. Operable } & 2.1 Keyboard accessibility & 2.1.1 Guarantee of keyboard use & $\circ$ \\
\hline & & 2.1.2 Focused movement & $\circ$ \\
\hline & $\begin{array}{l}2.2 \text { Provision of adequate } \\
\text { time }\end{array}$ & 2.2.1 Response-time control & $\circ$ \\
\hline & & 2.2.2 Provision of stop function & $\circ$ \\
\hline & $\begin{array}{l}2.3 \text { Prevention of light- } \\
\text { sensitive seizure }\end{array}$ & $\begin{array}{l}\text { 2.3.1 Restriction of flickering and } \\
\text { brightness }\end{array}$ & $\circ$ \\
\hline & 2.4 Easy navigation & 2.4.1 Repeated region skipping & $\circ$ \\
\hline & & 2.4.2 Provision of titles by page & $\circ$ \\
\hline & & 2.4.3 Proper text link & $\circ$ \\
\hline \multirow[t]{6}{*}{ 3. Understandable } & 3.1 Legibility & 3.1.1 Display of basic language & $\circ$ \\
\hline & 3.2 Predictability & $\begin{array}{l}\text { 3.2.1 Implementation according to } \\
\text { user requirement }\end{array}$ & $\circ$ \\
\hline & 3.3 Content logicality & 3.3.1 Content linearization & $\circ$ \\
\hline & & 3.3.2 Table configuration & $\circ$ \\
\hline & 3.4 Input help & 3.4.1 Label provision & ० \\
\hline & & $\begin{array}{l}\text { 3.4.2 Provision of error correction } \\
\text { function }\end{array}$ & $\times$ \\
\hline 4. Robust & 4.1 Grammar compliance & 4.1.1 Prevention of markup error & $\circ$ \\
\hline $\begin{array}{l}\text { (Technology } \\
\text { Progressiveness) }\end{array}$ & $\begin{array}{l}4.2 \text { web application } \\
\text { accessibility }\end{array}$ & $\begin{array}{l}\text { 4.1.2 web application accessibility } \\
\text { compliance }\end{array}$ & $\circ$ \\
\hline
\end{tabular}

\section{Results}

Twenty-five institutions that were selected as assessment targets in this study obtained a Web-content certification mark from the National Information Society Agency through a Web accessibility assessment using automated tools. According to an experts assessment using web accessibility, "Perceivable" among the four guidelines, was complied with an average of 3.4 items among a total of five items, thus showing the highest compliance rate $(68 \%)$ among the four. "Operable," "Understandable," and "Robust" complied with the averages of 5.16, 2.96 and 0.56 items respectively, showing the compliance rates of 64.5, 59.2, and $28 \%$ respectively (see Table 5).

\section{Perceivable}

The purpose of "Perceivable" in web accessibility is to understand contents using human senses such as sight and hearing. 
Table 5 Website Accessibility Compliance Items of Each Institution

\begin{tabular}{|c|c|c|c|c|c|}
\hline Requirement & Perceivable & Operable & Understandable & Robust & Total \\
\hline Agency & 5 items & 8 items & 5 items & 2 items & 20 items \\
\hline RE01 & 3 & 6 & 2 & 0 & 11 \\
\hline RE02 & 2 & 7 & 3 & 0 & 12 \\
\hline RE03 & 4 & 7 & 2 & 0 & 13 \\
\hline RE04 & 4 & 4 & 4 & 0 & 12 \\
\hline RE05 & 4 & 8 & 4 & 0 & 16 \\
\hline RE06 & 3 & 7 & 3 & 0 & 13 \\
\hline RE07 & 3 & 3 & 2 & 0 & 8 \\
\hline RE08 & 4 & 6 & 3 & 0 & 13 \\
\hline RE09 & 4 & 6 & 3 & 0 & 13 \\
\hline RE10 & 4 & 6 & 3 & 0 & 13 \\
\hline RE11 & 3 & 3 & 3 & 0 & 9 \\
\hline RE12 & 3 & 5 & 3 & 0 & 11 \\
\hline RE13 & 3 & 4 & 3 & 0 & 10 \\
\hline RE14 & 4 & 4 & 2 & 1 & 11 \\
\hline RE15 & 4 & 4 & 4 & 1 & 13 \\
\hline RE16 & 4 & 8 & 4 & 2 & 18 \\
\hline RE17 & 2 & 4 & 3 & 1 & 10 \\
\hline RE18 & 2 & 5 & 2 & 1 & 10 \\
\hline RE19 & 4 & 7 & 3 & 2 & 16 \\
\hline RE20 & 3 & 4 & 3 & 2 & 12 \\
\hline RE21 & 4 & 3 & 3 & 2 & 12 \\
\hline RE22 & 4 & 3 & 4 & 2 & 13 \\
\hline RE23 & 5 & 4 & 3 & 0 & 12 \\
\hline RE24 & 3 & 5 & 3 & 0 & 11 \\
\hline RE25 & 2 & 6 & 2 & 0 & 10 \\
\hline Average & 3.4 & 5.16 & 2.96 & 0.56 & 12.08 \\
\hline Maximum & 5 & 8 & 4 & 2 & 18 \\
\hline Minimum & 2 & 3 & 2 & 0 & 8 \\
\hline
\end{tabular}

The items to assess "Perceivable" include the provision of proper replacement text, subtitle provision, content perception irrelevant to color, provision of definite instructions, prohibition of the use of background sound, etc. According to the "Perceivable" assessment, for the criteria of satisfying the five related requirements, there was only one website that complied. On the other hand, websites satisfying the four requirements were twelve. Thus, only four websites satisfied two of the "Perceivable" items.

More specifically, institutions complying with proper replacement text provision and subtitle provision are nine and seven, respectively. Such is less than half of the 25 assessment targets. Perception of contents with regard to color and the prohibition of the use of background sound were complied with by all assessment targets. Provision of definite instructions was complied with by most institutions. Some institutions did not comply with a couple of their important pages. Some websites provided insignificant 
replacement texts such as "photo, user image" for photos that convey meaning, or provided an image file name as the replacement text.

Provision of replacement text is the most fundamental and significant item in the application of web accessibility. Contents can be classified into text, image, video, and file. For the provision of replacement text, when an image cannot be perceived because of environmental or physical factors, such as blindness, it is necessary to provide replacement information in text form so that it may be perceived. Contents in other forms than text, or factors that cannot be transformed into sound through a screen reader, such as images or image maps, are transformed into sound by explaining in detailed text using the "alt" tag.

In the case of the absence of replacement text, a disabled person will not be able to obtain information about an image. The existence of many websites that do not comply with an item of replacement text provision means that proper contents are not provided for users in a special class who must use screen readers. Also, it means that in the end, users are unable to perceive the contents of an image (Hyun and Kim 2008). As the provision of replacement text for an image can be utilized when a search engine interprets image, both the disabled and ordinary people can receive benefits.

In a multimedia environment, videos are very effective contents for information transfer. While most websites provide video contents, enough consideration is not given to deaf people. In providing contents, such as videos, replacement information, such as subtitling, manuscript, sign language, and audio explanation should be provided as an essential component. Such move would allow both deaf people and blind people to have an exact understanding of the contents.

\section{Operable}

"Operable" means that users should be able to easily operate a user interface that is provided to use the contents on websites. Websites should not provide contents in a manner that would be difficult for users to operate.

The items to assess "Operable" include a guarantee of keyboard use, focused movement, response-time control, stop-function provision, restriction of flickering and sparkling, repeated region skipping, provision of titles by page, proper text link, etc. According to the requirements for Operable, the number of websites that satisfy all eight requirements for accessibility is only two among a total of 25 sites. The number of websites that satisfy more than five items is 14 (56 \%). Many websites complied with Operable requirement the most among the four principles of web accessibility.

In particular, most websites complied well with repeated region skipping, restriction of flickering and sparkling, response-time control, and guarantee of keyboard use. The number of websites that comply with two items, such as focus movement and provision of titles by page, was just seven ( $28 \%$ ) and five (20\%), respectively. Most websites did not sufficiently provide meta-information such as title, description, and keywords. In particular, most websites did not grant a unique title to each page.

Every page should provide a title that easily tells the contents of the page. A user can avoid confusion in searching the web because he/she can easily understand what document he/she is looking at simply by looking at the title. Proper titles provided by page will help users to easily grasp what contents are included in the related document when they move between pages. 


\section{Understandable}

"Understandable" means that a user can easily understand the contents provided on a website or a user interface.

The items to assess "Understandable" are basic language expression, execution according to user requirement, content linearization, table configuration, label provision, etc. According to the assessment of the Understandable requirements, there was no website that satisfied all five requirements for accessibility. The number of websites that satisfied four requirements was five (20\%) among a total of 25 websites. Most of websites complied with three among five requirements of "Understandable," and the number of websites that complied with only two requirements was six.

More specifically, most of websites complied well with basic language expression and execution according to user requirements. Nineteen websites complied with label provision. Two requirements, such as content linearization and table configuration belonging to content logicality, were complied with by five and one site, respectively. The reason why most websites failed to satisfy these two requirements was not because of technological difficulties. It was because sufficient education has not been conducted.

The sequence of contents shown on the browser's screen is not always identical to the arrangement sequence of contents included in a web page. Content linearization means to check whether assistive devices ${ }^{1}$ used by disabled people grasp contents in the right sequence. In other words, it is to check whether the website contents-which are composed of upper menu, left menu, text, and lower menu-are structured in the right sequence. The contents that comprise a web page should be made to logically understand the contents when they are linearized and arranged in the right sequence. It should be provided in a manner that would enable understanding in a logical sequence through assistive devices.

When data is provided in table format, a web page should be configured so that blind people can also understand the contents and structure of a table. The information in which the contents are summarized is provided in a title or a summary on a table so that its contents can be inferred.

\section{Robust}

The target of the fourth principle, "Robust," specified in KWCAG 2.0 is web contents. "Robust," as part of the web accessibility principle, is also expressed as technology progressiveness. This means that users should be able to access the contents provided by a current website using this technology, no matter what technology may be developed in the future or the present. In other words, users should be able to access the contents on a website no matter what browser or device users may have. For this, web contents should comply with the markup language grammar and web application accessibility.

According to the assessment results of the "Robust" requirements for web contents, the number of websites that satisfied all two requirements of accessibility was just five. The number of websites that satisfied markup error prevention and web application accessibility compliance was nine and five, respectively. The reason why most of institutions did not comply with this item compared with other web accessibility principles is that they did not perceive the merits they can get by complying with web accessibility.

If a web page is configured so that the "start" tag and "end" tag can correspond well to each other and the inclusion relation of the tag will not go wrong when using the 
markup language factors, web browsers or assistive devices can convey the contents clearly without stopping its work processes. The web application needed to implement the function of a web page or an additional web application included in web contents should be created using the API function accessibility provided by an operating system. Otherwise, assistive devices may not support the accessibility function of a web application.

The functions (link, format, button, and page title) that can be implemented through markup language should not only be implemented through Java script because if they only depend on it, the link, format, button, and page title may not be implemented in an environment where such implementation is impossible.

\section{Open innovation and web accessibility}

Open Innovation matters in web accessibility in both humanities and technologies. Open innovation brings wealth of collective consensus for the goods of web standards embraces.

To satisfy the web standards, both humanities and technologies should be fully leveraged. Understanding that web accessibility benefits the content providers and the users alike makes the big difference in securing required budget, training, and peace of mind as well. The benefits web standards bring in will motivate the content providers to offer more web accessibility compliant websites. In particular this will make the big difference in the commercial sectors. The newly emerging silver market cannot be ignored from the commercial perspective. All of these mind set changes should be well noted among the decision makers, web designers, programmers, and all those involved in the entire website creation and maintenance eco system.

From technological perspective, to meet web accessibility standards largely requires the proper selection and use of software products and other related digital assets. All of these in principle rely upon open innovation. Many innovators around the globe came up with sophisticated web standards and accessibility development software including content management systems, frontend development frameworks, and other required snippets. Fortunately, most of them are freely and publicly available to all those in demand for such innovative technologies. For common wealth of all, many are released in MIT, Apache, LGPL, BSD license which helps all users free of any possible legal issues or burdening license fee. Such open innovations coupled with open source and quite often free software has been contributing the wide spread of mutually beneficial websites ever since the birth of web.

JQuery, a java script library, is a fine example of how open and collaborative knowledge helps wide spread out open innovation exponentially. Open innovation mind and technology in open innovation forms made the very positive difference to the global community. JQuery has almost all the required features for modern websites including dynamic effects while providing the web accessibility features. Without the innovative features provided by JQuery, web accessibilty and dynamic effects and pleasant user experiences will hardly co-exist. Now, all new modern websites cannot be produced without JQuery.

Another example involves the open knowledge sharing and collaborative knowledge growth eco-system. This site provides almost all the goodies required for wonderful websites and accessibility compliance. Initially supported by selected innovators, and 
further fueled by participating contributors almost all the required markup languages, java scripts, etc. are provided and community users and contributors ensure no questions are left unanswered. This is a fine example of both warm hearted humanities and open innovations that eventually benefits all the players in the eco-system. After all what matters in open innovation matters in common wealth of humans (see Table 6).

\section{Discussions and conclusion}

As a web interface design that is centered on young and middle-aged people can further widen the digital gap with the widespread use of the internet and diversification of users, it is necessary for us to make efforts to take in consideration the informationvulnerable class of people such as the elderly, the disabled, and children, etc.

Korea has recently started to conduct activities for web accessibility-the law and regulation strengthening, standardization, education, perception enhancement activity, etc. web accessibility ensures the free use of the internet for the socially disadvantaged people such as the disabled, etc. Although accessibility is focused on disabled people, it also provides benefits to institutions, as well as elderly users, mobile phone users, and other individuals.

Some point out that only a Web accessibility assessment item based on national standard guidelines has limits in improving web accessibility for disabled people. As websites should generally comply with web accessibility, regardless of site quantity or the diversity of content type, sites with larger size and contents have a higher possibility in determining errors.

According to the findings of this study, the websites of most institutions satisfied only web accessibility requirements that were easy to mechanically handle. Although Web accessibility certification was obtained, it turned out that it is necessary to actively build and operate the websites in order to comply with the website standard and accessibility guidelines. The Web accessibility items that the assessment-target websites did not comply with well were the following: provision of proper replacement text, subtitle provision, focused movement, provision of titles by page, content linearization, table configuration, markup error prevention, and web application accessibility compliance.

Based on the findings of this study, we would like to suggest the following for the improvement of web accessibility.

First, web accessibility should be considered at the initial stage of website planning. Both system building and education should be taken in consideration in order to provide continuous accessibility support even after the website is built.

KIPFA (Korea internet Professionals Association) announced the investigation results on web standard and Web accessibility compliance in its project implementation, which targeted 700 domestic web institutions and enterprises in September 2013. According to the investigation results, institutions and general enterprises answered that the concept of web accessibility was ambiguous, and technological approach was difficult. They also expressed that a standardized Web accessibility technology model is necessary.

Second, three factors are considered necessary to successfully comply with web accessibility - a content management system (CMS) that supports web accessibility and web standard; a technological template coding that properly supports the global web standard; data that is entered after properly understanding the concept of web accessibility. 
Table 6 Results of Website Accessibility Assessment

\begin{tabular}{|c|c|c|c|c|c|c|c|c|c|c|c|c|c|c|c|c|c|c|c|c|c|c|c|c|c|c|}
\hline Test Item & RE01 & RE02 & RE03 & RE04 & RE05 & RE06 & RE07 & RE08 & RE09 & RE10 & RE11 & RE12 & RE13 & RE14 & RE15 & RE16 & RE17 & RE18 & RE19 & RE20 & RE21 & RE22 & RE23 & RE24 & RE25 & total \\
\hline $\begin{array}{l}\text { 1.1.1 Provision of proper } \\
\text { replacement of text }\end{array}$ & B & B & B & A & $A$ & $B$ & $B$ & A & A & B & B & B & B & A & B & A & $C$ & B & A & B & $A$ & B & $A$ & B & B & 9 \\
\hline 1.2.1 Provision of subtitle & A & NA & A & NA & B & NA & NA & NA & NA & A & NA & NA & NA & A & A & NA & NA & NA & NA & NA & NA & A & A & NA & NA & 7 \\
\hline $\begin{array}{l}\text { 1.3.1 Perception of content } \\
\text { irrelevant to color }\end{array}$ & A & A & A & A & $A$ & A & A & A & A & A & A & A & A & A & A & A & A & A & A & A & A & A & A & A & A & 25 \\
\hline $\begin{array}{l}\text { 1.3.2 Provision of clear } \\
\text { instructions }\end{array}$ & B & NA & A & A & $A$ & A & $A$ & $A$ & A & $A$ & A & A & $A$ & B & $A$ & A & B & B & A & A & $A$ & A & $A$ & $A$ & B & 19 \\
\hline $\begin{array}{l}\text { 1.3.4 Prohibition of the use } \\
\text { of background sound }\end{array}$ & $A$ & $A$ & $A$ & $A$ & $A$ & A & $A$ & A & A & $A$ & A & A & $A$ & A & $A$ & A & A & $A$ & A & A & A & A & $A$ & A & A & 25 \\
\hline $\begin{array}{l}\text { 2.1.1 Guarantee of keyboard } \\
\text { use }\end{array}$ & $A$ & $A$ & A & $A$ & $A$ & A & B & $A$ & A & $A$ & B & A & $A$ & B & $A$ & A & B & $A$ & A & A & $A$ & A & C & A & A & 20 \\
\hline 2.1.2 Focused movement & B & A & A & AA & A & A & B & B & B & A & B & B & B & B & B & A & B & B & A & B & B & B & B & B & B & 7 \\
\hline 2.2.1 Response-time control & A & A & A & NA & A & A & C & A & A & A & A & A & A & A & A & A & A & A & A & NA & NA & NA & A & A & A & 20 \\
\hline $\begin{array}{l}\text { 2.2.2 Provision of stop } \\
\text { function }\end{array}$ & A & A & $A$ & NA & $A$ & A & C & NA & A & A & B & A & C & NA & NA & A & A & $A$ & A & A & NA & NA & A & $A$ & $A$ & 16 \\
\hline $\begin{array}{l}\text { 2.3.1 Restriction of flickering } \\
\text { and sparkling }\end{array}$ & A & A & A & A & A & A & $A$ & A & A & A & A & A & A & A & A & A & A & A & A & A & NA & A & A & A & $A$ & 24 \\
\hline $\begin{array}{l}\text { 2.4.1 Repeated region } \\
\text { skipping }\end{array}$ & A & A & A & A & A & A & A & A & A & A & A & A & A & A & A & A & A & A & A & A & A & A & A & A & A & 25 \\
\hline $\begin{array}{l}\text { 2.4.2 Provision of titles by } \\
\text { page }\end{array}$ & C & B & B & A & A & B & C & A & B & B & C & C & C & A & B & A & B & C & B & B & B & B & B & B & B & 5 \\
\hline 2.4.3 Proper text link & A & A & A & B & A & A & A & A & A & B & B & B & B & B & B & A & B & B & A & B & A & B & B & B & A & 12 \\
\hline $\begin{array}{l}\text { 3.1.1 Display of basic } \\
\text { language }\end{array}$ & A & A & A & A & A & A & A & A & A & A & A & A & A & A & A & A & A & A & A & A & A & A & A & A & A & 25 \\
\hline $\begin{array}{l}3.2 .1 \text { Implementation } \\
\text { according to user } \\
\text { requirement }\end{array}$ & A & A & A & A & A & A & A & A & A & A & A & A & A & A & A & A & A & A & A & A & A & A & A & A & B & 24 \\
\hline 3.3.1 Content linearization & B & A & B & A & A & B & B & B & B & B & B & B & B & $B$ & A & $B$ & $B$ & $B$ & $B$ & $B$ & $B$ & A & $B$ & $B$ & $B$ & 5 \\
\hline
\end{tabular}


Table 6 Results of Website Accessibility Assessment (Continued)

\begin{tabular}{|c|c|c|c|c|c|c|c|c|c|c|c|c|c|c|c|c|c|c|c|c|c|c|c|c|c|c|}
\hline 3.3.2 Table configuration & $C$ & $C$ & C & C & B & B & C & B & C & B & B & $B$ & B & B & $B$ & $A$ & $B$ & B & B & $\mathrm{B}$ & B & $B$ & B & B & B & 1 \\
\hline 3.4.1 Label provision & B & B & B & A & A & A & NA & A & A & A & A & A & A & NA & A & A & A & B & A & A & A & $A$ & A & A & A & 19 \\
\hline $\begin{array}{l}\text { 4.1.1 Prevention of markup } \\
\text { error }\end{array}$ & C & C & B & B & B & C & B & B & B & B & B & B & B & A & A & $A$ & A & A & A & A & A & A & C & B & B & 9 \\
\hline $\begin{array}{l}\text { 4.1.2 web application } \\
\text { accessibility compliance }\end{array}$ & C & NA & NA & NA & NA & NA & NA & NA & NA & NA & NA & NA & NA & B & B & $A$ & B & B & $A$ & $A$ & A & A & NA & NA & NA & 5 \\
\hline
\end{tabular}

A: Accessibility guidelines are complied with; B: Accessibility guidelines are mostly complied with, but not in complete extent; C: Accessibility guidelines are not complied with; NA: Not measurable 
web standard content management system is a core engine of a home page. On the other hand, template coding is similar to a mold. Thus, web accessibility, mobile home page, search and PR optimization, coding optimization, etc., should also be considered in entering the contents.

Third, it is necessary to understand and solve the present system's problem that access is only possible under a special operating system and a browser. If the web accessibility guidelines are complied with, accessibility to web contents will be guaranteed, no matter what information device a user may use under any information technology environment.

What makes a website accessible can be simple or complicated, depending on factors such as content type, size and complexity of a site, as well as the development tools and environment. Many accessibility functions are easily satisfied if they are planned at the initial stage of the development or during the redesign of a website In particular, in the case of sites that include a special type of contents, such as multimedia and sites where "coding" is improperly created in standard XHTML markup from the beginning, considerable efforts may be required.

To enhance the website accessibility of Korean websites, it is necessary to investigate actual conditions, conduct professional education, hold seminars, establish standards, expand related technology research, foster experts, and reform laws and institutions for perception enhancement. Public institutions should not see web accessibility compliance as only mandatory; rather, they should actively utilize it for the PR and marketing of institutions as a preemptive measure. Furthermore, web accessibility compliance will be able to produce the effects that are useful in strengthening our global competitiveness.

\section{Endnote}

${ }^{1}$ Assistive devices refer to screen readers, screen enlargement programs, etc., which disabled people and elderly people use as tools to utilize computers or the internet.

\section{Authors' contributions}

ESJ and YBY participated in the design of the study. KRN, SJM, and MBK performed the website assessment and drafted the manuscript. ESJ, KRN, and SJM coordinated the paper. All authors read and approved the final manuscript.

\section{Competing interests}

The authors declare that they have no competing interests.

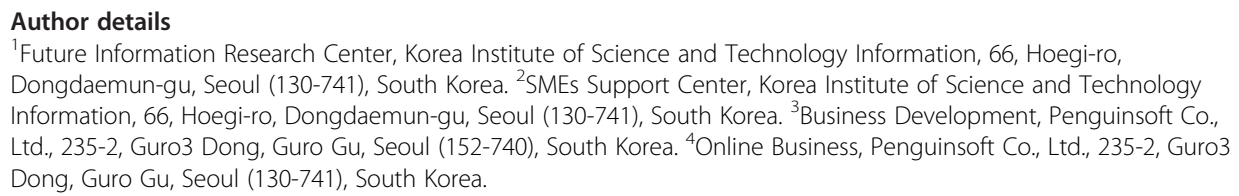

Received: 1 March 2015 Accepted: 31 May 2015

Published online: 26 August 2015

References

Chesbrough H, Vanhauverbeke W, West J. Open Innovation: Researching a New Paradigm. New York: Oxford University Press; 2006.

Hoover SJ. IT Professionals' Response to Adoption and Implementation of Innovations in the Workplace: Incorporating Accessibility Features into Information Technology for End Users with Disabilities, Doctoral dissertation, The University of Minnesota; 2003.

Hyun J, Choi D-j. Trend of foreign policy on Web accessibility and our counter plan. Digital Policy Res. 2003;1(1). Hyun J-h, Kim B-c. Current situation of Web accessibility compliance of domestic internet banking sites. Korea IT Serv Soc J. 2008;7(2):77-93. 
Jeong E, Moon S, Kim C, Yun I, Park B. Global online leadership strategies for public and private sectors. J Korea Technol Innov Soc. 2013;16(1):1-19.

Joo H-s. A study on the current situation of Web accessibility of public institutions and IT conglomerates. Korea Comput Inf Soc J. 2009;14(1):175-87.

Jung W, Hong S-K. A study on improvement plan of web accessibility for the disabled. J Internet Comput Serv. 2014;15(4):81-9.

Kang Y-M, Hong S-G, Lee H-M, Cha Y-S. Website accessibility evaluation of the welfare centers for the disabled. KAIS J. 2011;12(11):5260-71.

Kim J-M, Ryu H-G. A study on web contents accessibility of hospital websites in Korea. KAIS J. 2010;4(2):33-46.

Korea Communications Commission. Korean web Contents Accessibility Guideline 2.0. 2010.

Lee GH. The Comparative Study on observance of web Accessibility Guideline in Special school and General school with special class", Master's Thesis, the graduate school of Chonnam National University; 2012

Lee J-s, Lee B-s. Assessment of Web accessibility of domestic cyber university contents. Korea Contents Soc J. 2007;7(4):224-33.

National Information Society Agency. Trend of Web accessibility improvement to solve the problem of information gap. 2003.

News Wire. Urgency of Technical Standard Preparation for Improvement of Domestic Web accessibility; 2013.

Park M-Y, Ahn I-J, Park H-S, Kim I-h. Comparative study of web accessibility for visually impaired people in scientific and technical retrieval system and web contents. J Korean BIBLIA Soc Libr Inf Sci. 2010;21(3):123-37.

Web Accessibility Laboratory. http://www.wah.or.kr/participation/guide.asp.

Web Content Accessibility Guidelines (WCAG) 2.0. http://www.w3.org/TR/WCAG20/

Weigel FK, Hazen BT, Cegielski CG, Hall DJ. Diffusion of Innovations and Theory of Planned Behavior in Information Systems Research: A Meta-analysis," Communication of the Association for Information Systems, vol. 34. 2014

Yun JJ, Avvari MV, Jeong E-S, Lim D-W. Introduction of an objective model to measure open innovation and its application to the information technology convergence sector. Int J Technol Policy Manag. 2014;14(4):383-400.

Submit your manuscript to a SpringerOpen ${ }^{\circ}$ journal and benefit from:

- Convenient online submission

- Rigorous peer review

- Immediate publication on acceptance

- Open access: articles freely available online

- High visibility within the field

- Retaining the copyright to your article

Submit your next manuscript at $>$ springeropen.com 